\title{
Pulsed Low Intensity Electromagnetic Field (PEMF) Affects Cell Cycle of Human Osteoblast-like Cells in Vitro
}

\author{
Nahum Rosenberg ${ }^{*}$, Orit Rosenberg, Michael Soudry
}

Laboratory of Musculoskeletal Research, Orthopaedic Surgery “A” Department, Rambam, Health Care Campus, Haifa, 31096 , Israel

\begin{abstract}
High frequency electromagnetic field in the range of $4-33 \mathrm{kHz}$ given in low frequency bursts of 7-15 $\mathrm{Hz}$ (PEMF) is efficient in stimulating osteoblast proliferation and differentiation in vitro. We hypothesize that osteoblast cell cycle changes following this stimulatory PEMF. In order to explore this effect we used primary explant cultures of human osteoblast-like cells. These cells were subjected to low frequency of $20-30 \mathrm{~Hz}$, higher frequency of $5-15 \mathrm{kHz}$ electro magnetic fields and to PEMF $(5-15 \mathrm{kHz}$ basic frequency in pulses of 20-30 Hz) with maximal magnetic flux of 10-12 Gauss. The maturation state of the cells was estimated by the measurement of cellular alkaline phosphatase activity and the overall cell death by the LDH activity in culture media. The cell cycle was analyzed by cytometry. The PEMF stimulation significantly increased the proportion of cells in the G1 phase $(\mathrm{p}<.001)$ and decreased the proportion of apoptotic and necrotic cells $(\mathrm{p}<.001)$, with parallel decrease in cellular alkaline phosphatase and media LDH activities. Pure $20-30 \mathrm{~Hz}$ or $5-15 \mathrm{kHz}$ electro magnetic stimu lations had no effect on these parameters. Therefore we show that PEMF with a basic frequency in the $\mathrm{kHz}$ range provided in pulses in the infrasonic range alters human osteoblast cell cycle by reducing cell death and cellular maturation.
\end{abstract}

Keywords PEMF, Osteoblast, Cell Cycle

\section{Introduction}

Pulsed electromagnetic fields (PEMF) are in a clinical use for treatment of deficient bone lesions in order to stimulate new bone formation. The mechanism of the increased bone formation by the PEMF is attributed to the osteoblast stimulation ${ }^{1}$ and to suppression of os teoclast bone resorption ${ }^{2}$ by affecting, among others, osteoblast induced osteoclast stimulation. There is evidence that specific PEMF paramete rs are ess ential for stimulation of osteoblast proliferation and differentiation and they are not identical in different studies. In general basic high frequency electromagnetic field in the range of $4-33 \mathrm{kHz}$ given in low frequency bursts of 7-15 Hz are found to be efficient in stimulating osteoblast proliferation and differentiation in vitro $1,3,4$. The maximal magnetic flux in these studies was in the range of 2-30 Gauss ${ }^{1,4}$. The mechanism of the osteoblast stimulation is based on the accumulation of cytosolic $\mathrm{Ca}^{+4}$, but its overall effect on cell cycle is not known.

We hypothesize that osteoblast cell cycle is changed following the stimulatory PEMF. For this purpose westudie $\mathrm{d}$ the cell cycle profile of cultured human osteoblast-like cells following exposure to a low intensity PEMF.

* Corresponding author:

nahumrosenberg@hotmail.com (Nahum Rosenberg)

Published online at http://journal.sapub.org/ajbe

Copyright (C) 2012 Scientific \& Academic Publishing. All Rights Reserved

\section{Methods}

Primary explant cultures of human osteoblast-like cells were used for the experiments. For this purpose bone chips of cancellous bone were prepared from disposable bone samples which were collected from proximal femora of six donors (three men, three women, age range 65-85 years) during fractured hip arthroplasties. No osteoarthritic changes in the femoral head were evident under direct inspection. The samples were collected from the femoral canal, at least 4 centimeters distant from subchondral area. The bone samples, 2 - 3 grams in total each, were incubated in osteogenic medium 5,6, e.g. DMEM (Dulbecco's Modified Eagles Medium, Biological Industries Ltd) with heat-inactivated fetal calf serum (10\%), $20 \mathrm{mM}$ HEPES buffer, $2 \mathrm{mM}$ L-glutamine, $100 \mu \mathrm{M}$ ascorbate-2-phosphate, $10 \mathrm{nM}$ dexametasone, $50 \mathrm{U} / \mathrm{ml}$ penicillin, $150 \mu \mathrm{g} / \mathrm{ml}$ streptomycin, at $37^{\circ} \mathrm{C}$ in humidified air with $5 \% \mathrm{CO}_{2}$ (v:v), for $20-30$ days. Human osteoblast-like cells grow out from the chips are adherent to the plastic tissue culture plates (non-pyrogen ic polysterene). The human bone cell cultures obtained by this standard method have been shown previously to express osteoblast-like characteristics, i.e. polygonal multipolar morphology, expression of the enzyme alka line phosphatase, synthesis of a collagen-rich extracellular matrix with predominantly type I collagen and smalla mounts of collagen type III and V, and non-collagenous proteins such as 
sialoprotein (BSP) and osteocalcin ${ }^{5,6}$. Additionally these cells demonstrate matrix mineralization in vitro and bone formation in vivo 5,6. Furthermore, we have previously shown the osteoblast characteristics of these cells, including positive Von Kossa staining, synthesis of osteopontin, characteristic multipolar morphology and adherence to plastic surface, as well as cellular alkaline phosphatase and osteocalcin content ${ }^{7}$.

In the present study, cells were allowed to migrate from the bone chips into the medium, and proliferate in $75 \mathrm{~cm}^{2}$ culture flasks for 21 days. Then the cells were passaged into 24 well plates, where each well was seeded with $10^{4}$ cells. The cells were counted by direct microscopic inspection and kept at the same conditions prior to experiment commencement.

The use of these cells for the experiments was approved by the Institutional Ethical Committee.

The cultures were subjected to sine shaped low frequency of $20-30 \mathrm{~Hz}$ and higher frequency of $5-15 \mathrm{kHz}$ electromagnetic fields and to PEMF, i.e. $5-15 \mathrm{kHz}$ basic frequency in pulses of 20-30 Hz (Figure 1).

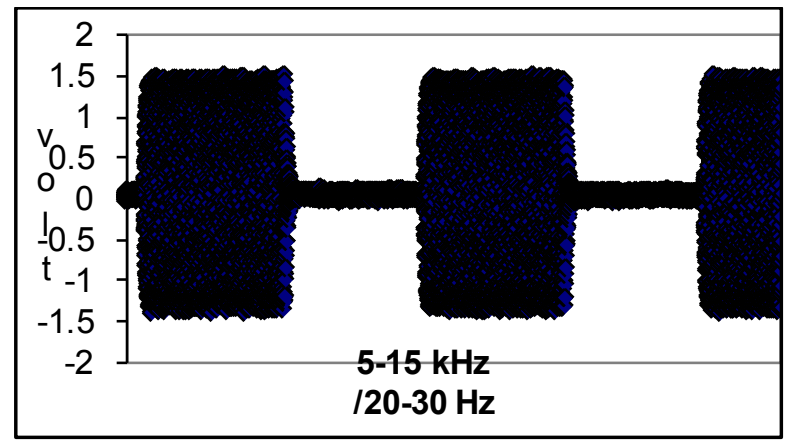

Figure 1. Profile of a electromagnetic field with the basic frequency of $5-15 \mathrm{kHz}$ in bursts of 5-15 kHz (PEMF) that was delivered to the cultured cells

The maximal magnetic flux was in the range of 10.00-12.00 Gauss. We used a specially designed system for delivery of electromagmetic field to human osteoblast-like cells in culture in 24 well plate, by placing a coil under each well (Figure 2). We used cultures of cells unexposed to magnetic fields as the study controls.

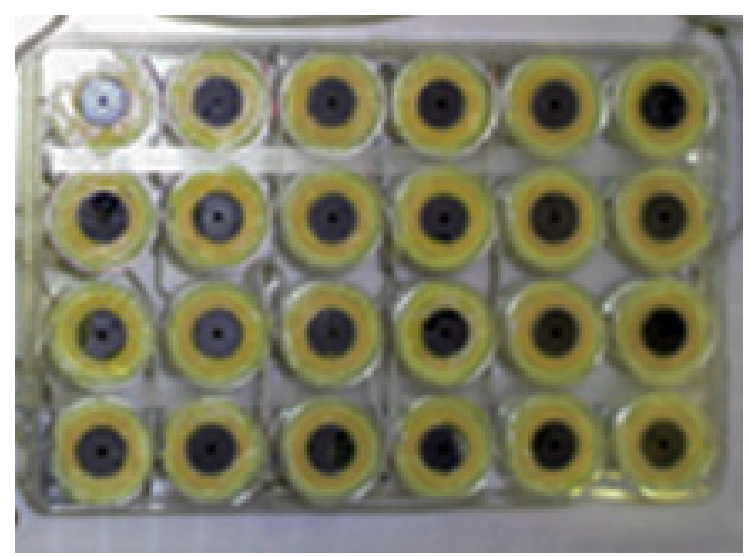

Figure 2. 24 well plate with cultured osteoblast-like cells is mounted on the coils that deliver controlled electromagnetic field
The exposure of the cultured cells to different electrlo magnetic fields was done in two hours periods with 1 hour interval once in 24 hours. We repeated this procedure in four consecutive days. The design on this protocol was empirical, and based on different clin ical protocols used with PEMF for enhancement of bone healing and on the previous in vitro studies involving osteoblasts 8 . Eight hours after the last exposure to the electromagnetic field the cell cultures were assayed.

The maturation state of the osteoblasts was estimated by the measurement of cellular alkaline phosphatase activity. Briefly, following cell counting in each culture sample the med ia were collected for the further assay and the adherent to the plastic surface cells were washed by PBS and lysed in $10 \%$ Triton X-100 and by three cycles of freezing to $-20^{\circ} \mathrm{C}$ and thawing at $20^{\circ} \mathrm{C}$. Alkaline phosphatase activity was determined in the lysed cell culture samples, after incubation with P-nitrophenyl phosphate substrate, using $410 \mathrm{~nm}$ wavelength spectrophotometry ${ }^{9}$.

LDH activity in culture media, due to leakage via damaged cell membranes, indicates the overall cell death. The LDH activity in the collected culture media fro $m$ treated samples and controls was determined by $340 \mathrm{~nm}$ wavelength spectrophotometry of a reduced Nicotinamide adenine dinucleotide (NAD), which is directly proportional to the LDH activity ${ }^{10}$.

The results were normalized to the cell number in each sample, which was counted by a direct inspection in a low power microscopic field.

Flow cytometric analysis was used to determine the cell cycle of the osteoblast-like cells. We used the FACScan flow cytometer (Becton Dickinson, San Jose, CA, USA). 10,000 cells were collected per assay point. Data was analyzed by the CELLQuest software package for determination of the number of cells in each cell cycle step.

The results were compared to control cultures unexposed to magnetic fields. Six samples for each condition were assayed.

Statistical co mparison was done by the $t$ test after a normal distribution of values was found in all studied groups of samples. P values below .05 were considered as indication of a significant change in comparison between the groups of values.

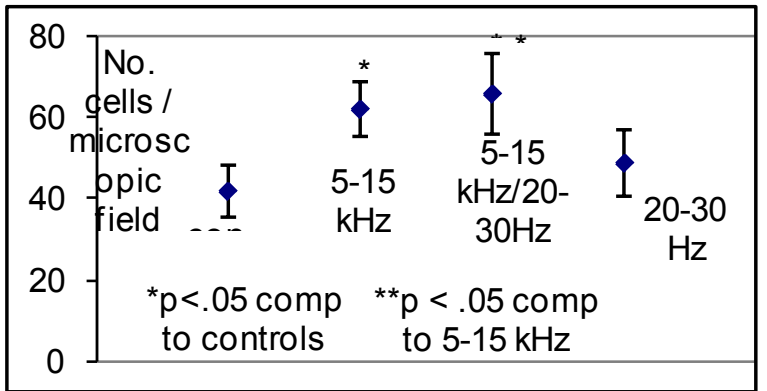

Figure 3. Number of cells in a low power microscopic field following exposure to different electromagnet ic protocols. Mean values and SD are presented $(n=6)$. Significantly higher values following exposure to PEMF are evident 


\section{Results}

The number of cells increased following exposure to 5-15 $\mathrm{kHz}$ basic electromagnetic frequency $(\mathrm{p}<0.05)$. Additionally when $5-15 \mathrm{kHz}$ electro magnetic field was delivered in pulses of 20-30 Hz a highest increase in cell number was observed (Figure 3).

Both cellular alkaline phosphatase and medium LDH activities decreased following exposure to PEMF (Figure 4).

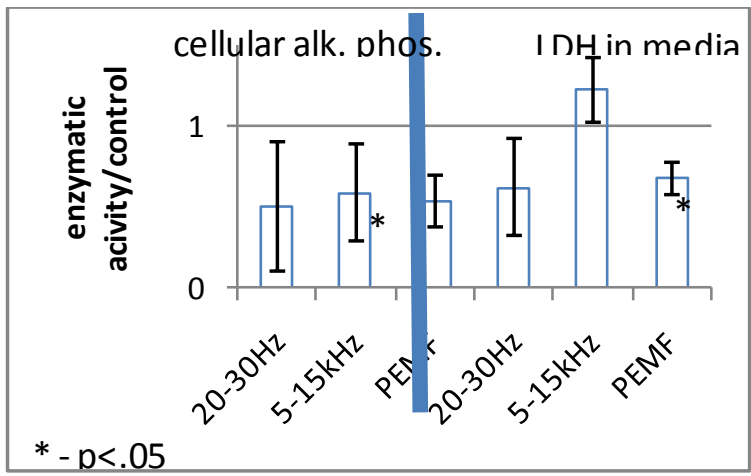

Figure 4. Activity of cellular alkaline phosphatase and LDH in culture media per cell following different protocols of electromagnetic exposure normalized to controls. Mean values and SD are presented $(n=6)$. Significantly lower values following exposure to PEMF are evident

When a $20-30 \mathrm{~Hz}$ or $5-15 \mathrm{kHz}$ frequency electro magnetic fields were applied to the cultured cells no significant change in cellular alkaline phosphatase activity and medium LDH activity was found ( $\mathrm{p}>.05$, Figures 4$)$.

Flow cytometric analysis (FACS) of the cells exposed to the $20-30 \mathrm{~Hz}$ or $5-15 \mathrm{kHz}$ frequency electromagnetic field also showed no difference in the cell cycle profile comparing to the controls $(p>.05)$. But the PEMF stimulation did significantly increase the proportion of cells in the G1 phase $(p<.001$, Figure 5) and decrease the proportion of apoptotic and necrotic cells $(\mathrm{p}<.001$, Figure 5$)$.

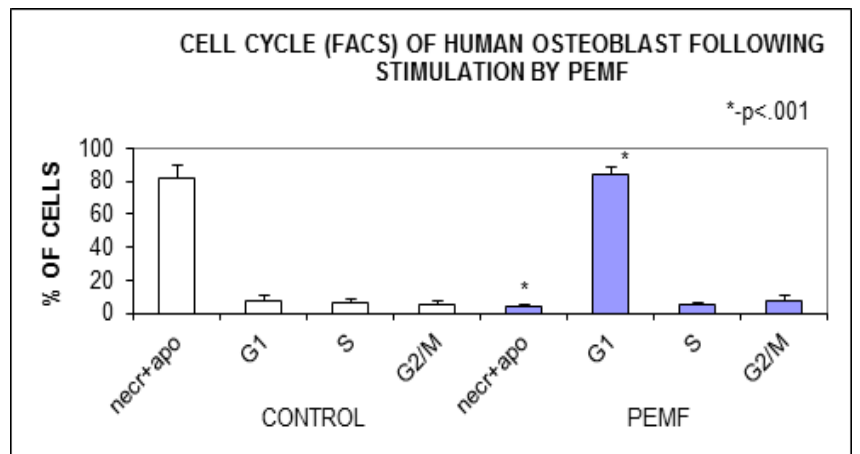

Figure 5. Cytometric profile of cells exposed to PEMF and cont rol cult ure. Shift ing of the cell cycle toward G1 phase in the cells exposed to the PEMF is evident. necr - necrotic cells, apo - apopt otic cells

\section{Discussion}

Electromagnetic field of $5-15 \mathrm{kHz}$ frequency delivered in 20-30 Hz pulses (PEMF) shifted the cultured human osteoblast-like cells toward G1 phase of the cell cycle on the expense of the proportion of necrotic and apoptotic cells.
This decrease of cell death caused an increase of cell number in the culture. The increase of cell number following the PEMF shouldn't be attributed to a mitogenic activity, because the $\mathrm{S}$ and $\mathrm{G} 2 / \mathrm{M}$ phases of the cell cycle were not altered by the PEMF. This observation of the decreased cell death rate following PEMF is supported by lower activity of LDH in culture media which is not observed following 20-30 $\mathrm{Hz}$ or $5-15 \mathrm{kHz}$ electromagnetic stimulation. In parallel to the decrease of cell death PEMF caused a suppression of osteoblast maturation, which is expressed by a lower alkaline phosphatase activity. This phenomenon wasn't observed following the pure $20-30 \mathrm{~Hz}$ or $5-15 \mathrm{kHz}$ stimulation.

The presented results support the previously reported evidence that rat osteoblast-like cells respond by maturation inhibition following PEMF of 15 Gauss in pulses of $48 \mathrm{~Hz}$ with parallel shifting of their cell cycle from $\mathrm{G} 2 / \mathrm{M}$ and $\mathrm{S}$ phases ${ }^{11}$.

A different effect was previously shown by Chang WHS et al, when mice osteoblast-like cells responded by a higher proliferation rate, without change in their maturation state, following exposure to PEMF with magnetic field of 1 Gauss $^{12}$. The difference from our results can be attributed to species origin of the cells, but probably the main reason is the differences in magnetic flux in these studies, 1 vs. 10-12 Gauss, and difference in exposure times to the PEMF, i.e. 8 hours vs. 4 hours daily. This diversity in cellular response with different physical parameters of PEMF should be taken into consideration when decision on the clinically optimal PEMF is made.

We found that the $5-15 \mathrm{kHz}$ electromagnetic stimulation cause some increase in cell number in the culture, but this weak increase wasn't accompanied by significant change in cellu lar alkaline phosphatase activity, LDH activity in the culture media and, most important, in the cell cycle profile. This indicates that the effect of $5-15 \mathrm{kHz}$ electromagnetic stimulation is of marginal importance.

\section{Conclusions}

We show that PEMF with a basic frequency in the $\mathrm{kHz}$ range delivered in pulses in the infrasonic range alters human osteoblast cell cycle by reducing cell death and cellular maturation. From these results we cautiously may suggest that by using the PEMF in vivo an increase of immature os teoblast pool in the exposed to the PEMF area might occur. The clinical significance of this phenomenon should be further investigated, especially after the cessation of the exposure to the PEMF, when subsequential unopposed by the PEMF osteoblast maturation allowing matrix elaboration, is expected.

\section{ACKNOWLEDGEMENTS}

This study was partially supported by the Appiades Meditech Ltd. 


\section{REFERENCES}

[1] Tsai MT, Chang WHS, Change K, Hou RJ, Wu TW. Pulsed electromagnetic fields affect osteoblast proliferation and differentiation in bone tissue engineering. Bio Electro Magnetics. 2007; 28: 519-528.

[2] Chang K, Chang WHS, Wu ML, Shih C. Effects of different intensities of extremely low frequency pulsedelectromagneti c fields on formation of osteoclast-like cells. Bio Electro Magnetics. 2003; 24: 431-439.

[3] Li JKJ, Lin JCA, Liu HC, Sun JS, Ruaan RC, Shih C, Chang WHS. Comparison of ultrasound and electromagnetic field effects on osteoblast growth. Ultrasound Med Biol. 2006; 32: 769-775.

[4] Brighton CT, Wang W, Seldes R, Zhang G, Pollak SR. Signal transduction in electrically stimulated bone cells. J Bone Joint Surg 83A. 2001; 1514-1523.

[5] Gundle R, Stewart K, Screen J, Beresford JN. Isolation and culture of human bone-derived cells. In: Beresford N, Owen ME, editors. Marrow stromal cell culture. Cambridge, UK: Cambridge university press; 43-66, 1998.

[6] Yamanouchi K, Satomura K, Gotoh Y, Kitaoka E, Tobiume S, Kume K, Nagayama M. Bone formation by transplanted human osteoblasts cultured within collagen sponge with dexamethasone in vitro. J Bone Mineral Res. 2001;16: 857-867.

[7] Rosenberg N, Soudry M, Rosenberg O, Blumenfeld I, Blumenfeld Z. The role of activin A in the human osteoblast cell cycle: A preliminary experimental in vitro study. Exp Clin Endocrinol Diabetes. 2010; 118: 708-712.

[8] Fitzsimmons RJ, Gordon SL, KronbergJ, Ganey T, Pilla AA. Apulsing electric field (PEF) increases human chondrocyte proliferation through a transduction pathway involving nitric oxide signaling. J Orthop Res. 2008; 26: 854-859.

[9] Bessey OA, Lowry OH, Brock MJ. A method for the rapid determination of alkaline phosphatase with five cubic millimeters of serum. J Biol Chem. 1946;164: 321-329.

[10] Gay RB, Bowers GN Jr. Optimum reaction conditions for human lactate dehydrogenase isoenzymes as they affect total lactate dehydrogenase activity. Clin Chem. 1968; 14:740-753.

[11] Wei Y, Xiaolin H, Tao S. Effects of extremely low frequency pulsed electromagnetic field on different derived osteoblast like cells. Electromagn Biol Med 2008;27: 298-311.

[12] Chang WHS, Chen LT, Sun JS, Lin FH. Effect of pulse-burst electromagnetic field stimulation on osteoblast cell activities. Bioelectromagnetics 2004; 25 457-465. 